\title{
CDISC SDTM Observational Study Model Terminology
}

National Cancer Institute

\section{Source}

National Cancer Institute. CDISC SDTM Observational Study Model Terminology. NCI Thesaurus. Code C127259.

Terminology associated with the observation study model codelist of the Clinical Data Interchange Standards Consortium (CDISC) Study Data T abulation Model (SDT M). 